\title{
A clinical study of lens induced glaucoma -retrospective analysis
}

\author{
Dr.V.M.V.R.V.Prasadarao M.S ${ }^{1, D r}$ D. M.Madhavi M.S, ${ }^{2}$,Dr. Zamrudh Shahin \\ M.S, ${ }^{3}$ Dr. Lakshmi Spandana M.S ${ }^{4}$ \\ ${ }^{1}$ professor Of Ophthalmology, Govt. Siddartha Medical College, Vijayawada, Ap \\ ${ }^{2}$ Assistant Professor Of Ophthalmology ${ }^{3}$ Senior Resident ${ }^{4}$ Senior Resident
}

\begin{abstract}
Objective: To determine the clinical presentation, management and outcome of lens-induced glaucoma $(L I G)$ in Govt. General Hospital attached to Govt. Siddhartha Medical College.

Methods: A retrospective study was done on LIG patients who have attended ophthalmic op Govt. General Hospital attached to Govt. Siddhartha Medical College Vijayawada during the period from 2010 September to 2015 August. Exclusively Patients with LIG were included and all patients with primary glaucoma's and secondary glaucoma's were excluded. Demographic data, clinical presentations, management and outcome were recorded and analyzed.

Results: Sixty four patients (64 eyes) with LIG were included. The mean age was 60years and predominantly women $(34,53.12 \%)$ were affected. Phacomorphic glaucoma (48, 75\%) was the main cause of LIG, followed by phacolytic glaucoma $(14,21.87 \%)$. The main clinical symptoms were reduced vision $(95 \%)$, eye pain $(88 \%)$ and eye redness $(82 \%)$. Most patients (51 eyes) were presented with visual acuity of hand movements $(79.6 \%$, or worse) and intraocular pressure more than $40 \mathrm{mmHg}$. Most of patients underwent Small incision cataract extraction with primary posterior chamber lens implantation.
\end{abstract}

Conclusion

Triad of acute eye pain reduced vision and redness are the main clinical presentations of LIG. The main cause of LIG is phacomorphic glaucoma stemming from untreated senile cataract. Public awareness and early detection by primary physician is important for an early intervention of cataract. Early intervention aids in visual recovery and IOP control of LIG.

Keywords: lens-induced glaucoma, cataract, phacomorphic glaucoma, phacolytic glaucoma

\section{Introduction}

Lens-induced glaucoma (LIG) is common in developing countries owing to the delay in cataract removal $(1,2)$ In India, cataract is one of the leading causes of blindness and low vision.()ㅡ Although LIG is prevalent in developing countries, it also occurs in developed countries(4) Lens-related elevation in intraocular pressure (IOP) results from a variety of mechanisms such as lens dislocation, lens swelling (intumescent cataract), inflammation due to phacoanaphylaxis and lens particle blocking the trabecular meshwork. Untreated increase in IOP damages the optic nerve mechanically, which inevitably leads to blindness. Elevation in IOP causes compression and backward bowing of lamina cribrosa, leading to obstruction of axoplasmic transport of retinal nerve fibre and ganglion cell death.

Cataract occurs when the crystalline lens loses its transparency normally as a part of the ageing process. Neglected cataract lens may swell because of the osmotic effect of the degenerated lens proteins. In phacomorphic glaucoma, the swollen lens may block the anterior flow of the aqueous humor from the posterior chamber pushing the iris forward. Eventually, the trabecular meshwork gets blocked by the iris and leads to a sudden and extreme rise in IOP. Prolonged swelling of the lens and hypermature cataract may cause disruption or dysfunction of the zonular fibres of the lens leading to subluxation of the lens. The change in the lens position blocks the anterior flow of the aqueous humour and subsequently causes elevated intraocular pressure (IOP) through the same mechanism mentioned above.() Other causes of subluxated lens include trauma, pseudoexfoliation syndrome, high myopia, buphthalmos and hereditary causes such as aniridia, Marfans syndrome and homocysteinuria. Trauma remains the most common cause of subluxated lens.

Phacolytic glaucoma is a principal complication of hypermature cataract. Hypermature cataract may cause leakage of lens protein from an intact capsule. The lens protein causes intense inflammation and blockage of trabecular meshwork, subsequently responsible for elevation of IOP.(ㅁ) The lens proteins and particles were thought to be derived from materials formed during the early embryological stage of eye development. The release of this material from a ruptured lens at the later life is perceived as foreign body and initiates an intense autoimmune granulomatous reaction.(7)

Understanding the presentation, causes and management of LIG are important for blindness prevention strategy. The purpose of this review is to study and determine the clinical presentations, management and 
outcome of lens induced glaucoma at General Hospital attached to Govt. Siddhartha Medical College, Vijayawada.

\section{Methods}

A retrospective review was conducted on the records of patients who were diagnosed with LIG and admitted to Govt. General Hospital attached to Govt. Siddhartha Medical College Vijayawada From 2010 september to 2015 Augest.. LIG was diagnosed based on the presence of elevated IOP and lens-related problem.(1) The diagnosis of phacomorphic glaucoma was based on the presence of the classical signs and symptoms such as pain and redness, shallow anterior chamber (AC), cornea oedema and increased IOP with intumescent lens. Phacolytic glaucoma was diagnosed clinically based on the presence of the hypermature cataract with intact capsule, presence of lens protein and flare in AC. Phacoanaphylactic glaucoma was diagnosed by the manifestation of the ruptured capsule, flare AC and increased IOP. The malposition of the lens (subluxation of the lens) was based on the slit lamp examination. Goldmann applanation tonometry was used to measure IOP.Exclusion criteria were applicable for those who had primary glaucoma or other underlying causes of secondary glaucoma, inadequate or inconclusive diagnostic data and less than 6 months of follow-up. Demographic data, clinical presentations, management and outcomes were documented and statistical analysis was conducted using IBM SPSS 20.0.

\section{Results}

A total of 64 patients with LIG (30 men and 34 women) were included in the review. Of the total patients, 48 (75\%) had phacomorphic glaucoma, 14 (21.87\%) had phacolytic glaucoma, 1 (1.56\%) had phacoanaphylactic glaucoma and $1(1.56 \%)$ had subluxated lens (Table 2). The results showed an increasing trend in the number of patients admitted for LIG from the year 2010 to 2015 (Table 2). The age of patients at the time of presentation was 47 to 88 years with the majority (71\%) between 61 and 80 years. Six (15.8\%) patients were between 81 and 90 years

Demographic Data
Table 1A
\begin{tabular}{|l|l|}
\hline & \\
Age & $\mathrm{N} \%$ \\
\hline Age in years (n=64) & \\
\hline $81-90$ & $2(12.5)$ \\
\hline $71-80$ & $20(31.25)$ \\
\hline $61-70$ & $26(40.62)$ \\
\hline $51-60$ & $8(12.5)$ \\
\hline $41-50$ & $2(3.12)$ \\
\hline
\end{tabular}

Table 1B

\begin{tabular}{|l|l|}
\hline Gender $(\mathbf{n}=64)$ & $\mathrm{N} \%$ \\
\hline Male & $30(46.87)$ \\
\hline Female & $34(53.12)$ \\
\hline
\end{tabular}

Table 2: Types Of Lig \& Number Of Lig Cases According To Year

Table 2A

\begin{tabular}{|l|l|}
\hline Types of LIG $(\mathrm{n}=64)$ & $\mathrm{N} \%$ \\
\hline Phacomorphic & $48(75)$ \\
\hline Phacolytic & $14(21.87)$ \\
\hline Phacoanaphylactic & $1(1.56)$ \\
\hline Subluxated Lens & $1(1.56)$ \\
& \\
\hline
\end{tabular}

Table 2B

\begin{tabular}{|l|l|}
\hline Status of fellow eye $(\mathrm{n}=64)$ & $\mathrm{N} \%$ \\
\hline Psedophakic & $10(15.62)$ \\
\hline Mature cataract & $4(16.25)$ \\
\hline Immature cataract & $48(75)$ \\
\hline & \\
Number of LIG cases according to year & $\mathrm{N} \%$ \\
\hline 2010 & 4 \\
\hline 2011 & 13 \\
\hline
\end{tabular}




\begin{tabular}{|l|l|}
\hline 2012 & 15 \\
\hline 2013 & 10 \\
\hline 2014 & 14 \\
\hline 2015 & 8 \\
\hline
\end{tabular}

\section{Clinical presentation-}

Most patients with LIG presented with reduced vision (95\%), eye pain (88\%), eye redness $(82 \%)$, headache (68\%) and vomiting (30\%) (Table 3). Despite the presence of reduction in vision, majority of patients presented late to the hospital. Almost half of them looked for the treatment only after 6 months and 1 year of reduction in vision. Eye pain and redness, were the main symptoms that brought the patients to the hospital.

Table 3 : Summary of clinical presentations of LIG

Table 3A Symptoms

\begin{tabular}{|l|l|}
\hline Symptoms(n=64) & N\% \\
\hline Reduced vision & $60(95)$ \\
\hline Eye pain & $56(88)$ \\
\hline Eye redness & $52(82)$ \\
\hline Headache & $43(68)$ \\
\hline Vomiting & $19(30)$ \\
\hline
\end{tabular}

Table 3B Visual acuity affected eye

\begin{tabular}{|l|l|}
\hline Visual acuity affected eye $(\mathbf{n = 6 4 )}$ & $\mathbf{N \%}$ \\
\hline $6 / 12-1 / 18$ & $4(6.25)$ \\
\hline $6 / 24-6 / 36$ & $2(3.125)$ \\
\hline $6 / 60-1 / 60$ & $6(9.37)$ \\
\hline CF(counting fingers) & $1(1.56)$ \\
\hline HM (hand movement) & $24(37.5)$ \\
\hline PL(perception of light) & $18(28.12)$ \\
\hline Non-perception of light (NPL) & $9(14.06)$ \\
\hline
\end{tabular}

Table 3C Intraocular pressure in $\mathrm{mmHg}$

\begin{tabular}{|l|l|}
\hline Intraocular pressure in $\mathbf{~ m m H g},(\mathbf{n}=64)$ & $\mathbf{N \%}$ \\
\hline$\geq 20-29$ & $8(12.5)$ \\
\hline$\geq 30-39$ & $8(12.5)$ \\
\hline$\geq 40-49$ & $26(40.62)$ \\
\hline$\geq 50-59$ & $9(14.06)$ \\
\hline$\geq 60-69$ & $12(18.75)$ \\
\hline$\geq 70-79$ & $1(1.56)$ \\
\hline
\end{tabular}

Table 4: IOP prior to operation and at discharge

\begin{tabular}{|l|l|}
\hline IOP(mmHg)prior to operation $(\mathbf{n = 6 4})$ & $26(40.62)$ \\
\hline$\geq 10-19$ & $22(34.37)$ \\
\hline$\geq 20-29$ & $8(12.5)$ \\
\hline$\geq 30-39$ & $6(9.37)$ \\
\hline$\geq 40-49$ & $2(3.12)$ \\
\hline$\geq 50-59$ & $56(87.5)$ \\
\hline IOP(mmHg)on discharge (n=64) & $7(10.93)$ \\
\hline$\geq 10-19$ & $1(1.56)$ \\
\hline$\geq 20-29$ & -- \\
\hline$\geq 30-39$ & -- \\
\hline$\geq 40-49$ &
\end{tabular}

Table 5: Visual acuity on admission, discharge and 6 months follow-up

\begin{tabular}{|l|l|}
\hline Visual acuity on admission $(\mathbf{n = 6 4 )}$ & - \\
\hline $6 / 6-6 / 9$ & $4(6.25)$ \\
\hline $6 / 12-6 / 18$ & $2(3.12)$ \\
\hline $6 / 24-6 / 36$ & $6(9.37)$ \\
\hline $6 / 60-1 / 60$ & $1(1.56)$ \\
\hline CF at variable distance & $24(37.8)$ \\
\hline H M & $18(28.12)$ \\
\hline PL & $9(14.06)$ \\
\hline NPL & \\
\hline Visual acuity on discharge $(\mathbf{n = 6 4 )}$ & $2(3.12)$ \\
\hline $6 / /-6 / 9$ & $6(9.37)$ \\
\hline $6 / 12-6 / 18$ & \\
\hline
\end{tabular}




\begin{tabular}{|l|l|}
\hline $6 / 24-6 / 36$ & $22(34.37)$ \\
\hline $6 / 60-1 / 60$ & $11(17.18)$ \\
\hline CF & $12(18.75)$ \\
\hline HM & -- \\
\hline PL & $2(3.12)$ \\
\hline NPL & $9(14.06)$ \\
\hline
\end{tabular}

\begin{tabular}{|l|l|}
\hline Visual acuity 6 months post-operation $(\mathbf{n = 6 4})$ & $24(37.5)$ \\
\hline $6 / 6-6 / 9$ & $18(28.12)$ \\
\hline $6 / 12-6 / 18$ & $4(6.25)$ \\
\hline $6 / 24-6 / 36$ & $4(6.25)$ \\
\hline $6 / 60-1 / 60$ & -- \\
\hline CF & $1(1.56)$ \\
\hline HM & -- \\
\hline PL & $9(14.06)$ \\
\hline NPL & $4(6.25)$ \\
\hline Missing data & \\
\hline
\end{tabular}

\section{Intraocular pressure, surgery and outcome}

Majority of patients underwent Small Incision cataract extraction (SICS) with and without IOL implantation. Other operations performed were intracapsular cataract extraction (ICCE). Majority of patients were implanted with IOL either posterior chamber intraocular lens (PCIOL) or anterior chamber type (ACIOL) On day 1 post-operation, IOP reduction below $20 \mathrm{~mm} \mathrm{Hg}$ was achieved in 48 (75\%) patients. Upon discharge, most patients $(34,89.5 \%)$ recorded IOP below $20 \mathrm{~mm} \mathrm{Hg}$ with or without using topical pressure-lowering drugs.

\section{Discussion}

In the present study, the phacomorphic lens is the most common cause of LIG followed by the phacolytic lens. In India, phacomorphic glaucoma was found in 3.9\% of all cataract surgeries. $\underline{8}$ Based on the retrospective review, The findings were similar to those of the previous studies, which indicated that women are more predisposed to LIG $\underline{9} \underline{10}$ due to higher prevalence of cataract in them.11, $\underline{12}$ Inaccessibility to eye care and lack of awareness may contribute to late presentation of LIG even with the presence of pain. Early detection of lens-related problem may prevent elevation of IOP, which may lead to optic neuropathy. Public awareness on the benefits of early detection and treatment of cataract is important in the prevention of LIG. The saying 'poor vision is associated with old age' needs to be eradicated $\underline{13}$

\section{Conclusion}

LIG is an important vision-threatening disease presenting as a painful red eye. A phacomorphic lens disease secondary to a neglected senile cataract is the major cause of LIG. Removal of the cataractous lens results in prompt reduction in IOP and a favorable visual outcome.

\section{References}

[1]. Jain IS, Gupta A, Dogra MR. et al. Phacomorphic glaucoma Management and visual prognosis. Ind J Ophthalmol. 1983;31:648-53.

[2]. Nilo Vincent DG, florcruz II, Raquel JQ. et al. Profile of glaucoma cases seen at tertiary referral hospital. Philipp J Ophthalmol. 2005;30(4):161-5.

[3]. Zainal M, Ismail SM, Ropilah AR. et al. Prevalence of blindness and low vision in Malaysian population: Results from the National Eye Survey 1996. Br J Ophthalmol. 2002;86(9):951-6.

[4]. Sowka J. Phacomorphic glaucoma: Case and review. Optometry. 2006;77:586-9.

[5]. Jonathan PE, Ellant, Stephen A. et al. Lens induced glaucoma. Documenta Ophthalmia. 1992;(81):317-38

[6]. Johns KJ, Feder RS, Hamill MB. et al. Lens and cataract. American Academy of Ophthalmology. 2002-2003

[7]. Zimmerman LE. Lens induced inflammation in human eyes. Maumenee AE, Silverstein AM, editors. Immunopathology of Uveitis. 1964:221-32. New York: Lippincott Williams \& Wilkins.

[8]. Pradhan D, Hennig A, Kumar J. et al. A prospective study of 413 cases of lens-induced glaucoma in Nepal. Indian J Ophthalmol. 2001;49:103-7.

[9]. Angra SK, Pradhan R, Garg SP. Cataract induced glaucoma-An insight into management. Indian J Ophthalmol. 1991;39:97-101.

[10]. Mohinder S, Hassan A, Revathy K. Intraocular lens implantation in phacomorphic glaucoma. Bahrain Medical Bulletin. 2002;24(3):88-90.

[11]. Chatterjee A, Milton R, Thyle S. Prevalence and aetiology of cataract in Punjab. Br J Ophthalmol. 1982;66:35-62.

[12]. Khan M, Hoque M, Khan MR. Prevalence and causes of blindness in rural Bangladesh. Indian J Med Res. 1985;82:257.

[13]. Applegate WB, Miller ST, Elam JT. et al. Impact of cataract surgery with lens implantation on vision and physical function in elderly patients. JAMA. 1987;257(8):1064-6. 